Tohoku J. Exp. Med., 2008, 214, 321-325

\title{
The Association between an Increased Level of Gamma- Glutamyl Transferase and Systolic Blood Pressure in Diabetic Subjects
}

\author{
Kazuhiko Kotani, ${ }^{1,2}$ Hisashi Shimohiro, ${ }^{3}$ Seiji Adachi ${ }^{4}$ and Naoki Sakane $^{2}$ \\ ${ }^{1}$ Division of Health Administration and Promotion, Faculty of Medicine, Tottori University, Yonago, \\ Japan \\ ${ }^{2}$ Department of Preventive Medicine and Diabetes Education, Clinical Research Center for Endocrine \\ and Metabolic Disease, National Hospital Organization Kyoto Medical Center, Kyoto, Japan \\ ${ }^{3}$ Division of Clinical Laboratory, Tottori University Hospital, Yonago, Japan \\ ${ }^{4}$ Division of General Medicine and Community Medicine, Fujii Masao Memorial Hospital, Kurayoshi, \\ Japan
}

Gamma-glutamyl transferase (GGT) is an enzyme present in serum and on most cell surfaces and serves as an oxidative stress marker. Although serum GGT is associated with hypertension development, little data are available on the associations between GGT and hypertension among populations with diabetes mellitus (DM). Our aim was to investigate the potential association between the changes in systolic or diastolic blood pressure (SBP/ DBP) and the GGT level in type 2 DM subjects, in comparison with non-DM subjects. In 179 non-DM and 177 DM subjects, SBP/DBP, body mass index (BMI), fasting plasma glucose, serum asparate aminotransferase, alanine aminotransferase and GGT were measured at the baseline and after a 1-year period. Between these 2-measurement points, in non-DM subjects, SBP and DBP levels were significantly increased, while GGT tended to increase. In contrast, in DM subjects, the mean levels of SBP, DBP and GGT remained unchanged. Multivariate analysis revealed that in non-DM subjects the degree of increase in SBP was significantly and positively correlated to that of GGT $(\beta=0.165)$, along with age and BMI. Likewise, the increase in DBP was correlated to that of GGT in non-DM subjects $(\beta=0.170)$. In contrast, in DM subjects, the degree of increase in SBP was significantly correlated to that of only GGT $(\beta=0.166)$. These results suggest that the presence of DM may attenuate the effects of GGT on DBP. - liver enzyme; gammaglutamyl transferase; body mass index; weight change.

Tohoku J. Exp. Med., 2008, 214 (4), 321-325.

(C) 2008 Tohoku University Medical Press

Gamma-glutamyl transferase (GGT) is an enzyme that is present in serum and on the surfaces of most cell types, and serum GGT is clinically used as a marker of alcohol consumption in general. Recently, serum GGT has been recognized as a marker of oxidative stress (OS) (Lee et al. 2004). Although the mechanism on the associations between GGT and OS remains largely unknown, some possible explanations exist: e.g., its direct involvement in the generation of reac-

Received November 15, 2007; revision accepted for publication February 15, 2008.

Correspondence: Kazuhiko Kotani, M.D., Ph.D., Division of Health Administration and Promotion, Faculty of Medicine, Tottori University, 86 Nishi-cho, Yonago 683-8503, Japan.

e-mail: kakotani@grape.med.tottori-u.ac.jp 
tive oxygen species, its indirect role to maintain intracellular antioxidant glutathione (in a response to OS, increased transport of glutathione into cells by increased GGT activity), its relation to chronic inflammation, or its relation to the pathophysiology of insulin resistance (Lee et al. 2003; Shankar and $\mathrm{Li} 2007$ ).

OS is involved in the pathophysiology of various diseases such as cardiovascular and/or metabolic regulation (Lee et al. 2004). In fact, increased serum GGT levels are implicated in an increased blood pressure (BP) and the progression of hypertension (HT) (Nilssen et al. 1990; Ikai et al. 1994; Lee et al. 2002, 2003; Stranges et al. 2005; Shankar and Li 2007). However, little data have been available on the associations between GGT and HT among populations with diabetes mellitus (DM) specifically, still more data regarding GGT change levels (over a period of at least 1 year to see a chronic influence) are needed. DM and HT are interrelated diseases predisposing to atherosclerotic cardiovascular disease: OS-related mechanisms can be hypothesized in this interrelationship (Lee et al. 2003). Accordingly, the association between GGT and BP levels among DM populations may have some specific characteristics, but there are not any data with a comparison to non-DM populations.

With these backgrounds in mind, we conducted a 1-year observational study to investigate the following outcome-of-interest: whether systolic/diastolic BP (SBP/DBP) level differences could be potentially associated with those of GGT in addition to other hepatic enzymes in type $2 \mathrm{DM}$ subjects, and whether the association between BP and GGT was different between type $2 \mathrm{DM}$ and non-DM subjects.

\section{Subjects ANd Methods}

In total, 356 asymptomatic Japanese subjects were studied during a 1-year study period between 2006 and 2007: there were 179 non-DM subjects (79 males and 100 females; mean age: $48.7 \pm 6.2$ [range: $36-64$ ] years) and 177 type 2 DM subjects (78 males and 99 females; mean: $50.5 \pm 6.5[35-65]$ years). This study was approved by the Tottori University Ethics Committee and each subject gave informed consent. These subjects were recruited from a general population for health check-ups. Type 2 DM was diagnosed through repeated doctor's checks for subjects with plasma glucose (PG) of $\geqq 7$ mmol/1 (World Health Organization criteria) in blood examinations both at the baseline and after a 1-year study period. Non-DM subjects showed persistent normal PG levels in similar examinations, and were apparently of normal health.

All subjects had had no medical history of cardiovascular, thyroid, renal or malignant disorders. They were negative for both hepatitis B surface antigen and hepatitis $\mathrm{C}$ virus antibody, had serum levels less than 2 -folds the upper limit of the reference range of each hepatic enzyme, did not take any continuous medication, and had not had an alcohol intake and smoking habits. They were untreated during the study period. For each subject, seated SBP/DBP was measured 3-times with an automatic electronic sphygmomanometer (BP-103i II; Nippon Colin, Komaki) and the 3 measurements were averaged. At the baseline, in addition to SBP/DBP and body mass index (BMI), fasting PG, serum asparate aminotransferase (AST), alanine aminotransferase (ALT) and GGT were measured. After the 1-year period, the same variables were reexamined. PG was assayed with an automatic analyzer (JCA-BM2250, JEOL Co. Ltd., Tokyo), and AST, ALT and GGT were also assayed with an automatic analyzer (TBA-200FR, Toshiba, Tokyo). These intraassay-coefficients of variation were $0.8 \%$ in PG, $0.5 \%$ in AST, $0.5 \%$ in ALT and $0.6 \%$ in GGT, respectively.

All values were expressed as mean \pm S.D. (regarding AST, ALT and GGT, geometric mean). Level differences between the data at the baseline and after a 1-year period were analyzed by paired $t$-test. A multiple regression analysis on level differences of SBP/DBP was used to analyze the correlation to those of GGT after adjusting for measured confounders (age, gender, BMI, AST and ALT). Because of their skewed distributions, AST, ALT and GGT were log-transformed and included in the analysis model. We used SBP/DBP as continuous variables and gender simply as an explanatory variable, since no threshold effects of GGT on BP levels and no clear gender-differences in the association between GGT and BP have been confirmed (Shankar and Li 2007). A level of $p<0.05$ was considered significant.

\section{RESUltS}

The data at baseline (pre-study period) and after 1 year (post-study period) on each measured 
variable in the non-DM and type 2 DM group were respectively listed in Table 1. During a 1-year period, in non-DM subjects, SBP and DBP levels were significantly increased, while GGT slightly increased. In contrast, in type $2 \mathrm{DM}$ subjects, the mean levels of SBP, DBP and GGT remained unchanged.

In non-DM subjects, the degree of increase in SBP was significantly, independently and posi- tively correlated to that of GGT, along with age and BMI (Table 2). Similarly, DBP were significantly, independently and positively correlated to GGT. On the other hand, in type 2 DM subjects, the degree of increase in SBP was significantly, independently and positively correlated to that of only GGT. Although a correlated tendency to GGT was observed, DBP did not show any relative significance.

TABLE 1. Pre- and post-study characteristics of each variable in the non-DM and type 2 DM group.

\begin{tabular}{|c|c|c|c|}
\hline Variable & Pre-study levels & Post-study levels & Level differences \\
\hline \multicolumn{4}{|l|}{ Non-DM group $(n=179)$} \\
\hline Systolic blood pressure $(\mathrm{mmHg})$ & $\begin{array}{r}116.8 \pm 15.1 \\
(83-155)\end{array}$ & $\begin{array}{c}120.0 \pm 15.3^{* *} \\
(91-168)\end{array}$ & $\begin{array}{c}2.9 \pm 9.7 \\
(-24-+26)\end{array}$ \\
\hline Diastolic blood pressure $(\mathrm{mmHg})$ & $\begin{array}{c}75.8 \pm 10.6 \\
(52-99)\end{array}$ & $\begin{array}{c}76.6 \pm 10.4^{*} \\
(50-101)\end{array}$ & $\begin{array}{c}1.4 \pm 7.7 \\
(-17-+19)\end{array}$ \\
\hline Body mass index $\left(\mathrm{kg} / \mathrm{m}^{2}\right)$ & $\begin{array}{c}22.3 \pm 2.4 \\
(17.1-29.3)\end{array}$ & $\begin{array}{c}22.5 \pm 2.5^{* *} \\
(16.8-29.5)\end{array}$ & $\begin{array}{c}0.2 \pm 0.7 \\
(-2.9-+2.8)\end{array}$ \\
\hline Glucose (mmol/l) & $\begin{array}{c}4.8 \pm 0.2 \\
(4.0-5.5)\end{array}$ & $\begin{array}{c}4.8 \pm 0.3 \\
(4.2-5.5)\end{array}$ & $\begin{array}{l}-0.02 \pm 0.23 \\
(-0.6-+1.1)\end{array}$ \\
\hline $\operatorname{AST}(\mathrm{U} / \mathrm{l})$ & $\begin{array}{r}18.6 \pm 1.4 \\
(10-52)\end{array}$ & $\begin{array}{l}20.1 \pm 1.4 * * \\
\quad(8-49)\end{array}$ & $\begin{array}{c}1.3 \pm 1.3 \\
(-15-+27)\end{array}$ \\
\hline ALT (U/l) & $\begin{array}{r}18.2 \pm 1.6 \\
(10-64)\end{array}$ & $\begin{array}{c}19.3 \pm 1.6^{* *} \\
\quad(7-69)\end{array}$ & $\begin{array}{c}1.1 \pm 1.3 \\
(-20-+26)\end{array}$ \\
\hline GGT (U/l) & $\begin{array}{r}30.0 \pm 1.5 \\
(11-70)\end{array}$ & $\begin{array}{r}31.0 \pm 1.5 \\
(12-79)\end{array}$ & $\begin{array}{c}1.0 \pm 1.4 \\
(-24-+44)\end{array}$ \\
\hline \multicolumn{4}{|l|}{ Type 2 DM group $(n=177)$} \\
\hline Systolic blood pressure $(\mathrm{mmHg})$ & $\begin{array}{r}122.9 \pm 19.1 \\
(80-169)\end{array}$ & $\begin{array}{r}122.1 \pm 17.9 \\
(82-169)\end{array}$ & $\begin{array}{l}-0.8 \pm 12.4 \\
(-38-+27)\end{array}$ \\
\hline Diastolic blood pressure $(\mathrm{mmHg})$ & $\begin{array}{c}79.3 \pm 11.6 \\
(51-99)\end{array}$ & $\begin{array}{c}79.2 \pm 10.9 \\
(50-99)\end{array}$ & $\begin{array}{l}-0.1 \pm 8.8 \\
(-25-+20)\end{array}$ \\
\hline Body mass index $\left(\mathrm{kg} / \mathrm{m}^{2}\right)$ & $\begin{array}{c}23.2 \pm 3.2 \\
(16.1-29.6)\end{array}$ & $\begin{array}{c}23.3 \pm 3.1 \\
(16.0-29.9)\end{array}$ & $\begin{array}{c}0.0 \pm 0.7 \\
(-3.7-+1.9)\end{array}$ \\
\hline Glucose (mmol/l) & $\begin{array}{c}7.2 \pm 0.3 \\
(7.0-9.8)\end{array}$ & $\begin{array}{c}7.4 \pm 0.5^{* *} \\
(7.0-11.1)\end{array}$ & $\begin{array}{c}0.19 \pm 0.30 \\
(-0.9-+1.7)\end{array}$ \\
\hline $\operatorname{AST}(\mathrm{U} / \mathrm{l})$ & $\begin{array}{r}20.4 \pm 1.4 \\
(10-65)\end{array}$ & $\begin{array}{r}21.2 \pm 1.4 \\
(11-61)\end{array}$ & $\begin{array}{c}1.0 \pm 1.3 \\
(-18-+30)\end{array}$ \\
\hline $\operatorname{ALT}(\mathrm{U} / \mathrm{l})$ & $\begin{array}{r}20.4 \pm 1.6 \\
(11-57)\end{array}$ & $\begin{array}{r}21.1 \pm 1.5 \\
(10-58)\end{array}$ & $\begin{array}{c}1.0 \pm 1.5 \\
(-42-+47)\end{array}$ \\
\hline GGT (U/l) & $\begin{array}{r}31.4 \pm 1.5 \\
(12-62)\end{array}$ & $\begin{array}{r}30.0 \pm 1.6 \\
(10-67)\end{array}$ & $\begin{array}{l}-1.0 \pm 1.6 \\
(-43-+41)\end{array}$ \\
\hline
\end{tabular}

Data are shown as mean \pm S.D. and ranges are in parentheses. DM, diabetes mellitus; AST, aspirate aminotransferase; ALT, alanine aminotransferase; GGT, gamma-glutamyl transferase.

Level differences between pre- and post-study data were analyzed by paired $t$-test.

Significance levels: $* p<0.05, * * p<0.01$. 
TABlE 2. Multiple regression analysis of variables correlated to blood pressure level differences.

\begin{tabular}{|c|c|c|}
\hline \multirow{2}{*}{ Variable } & Non-DM group & Type 2 DM group \\
\hline & $\beta$-coefficient ( $p$ value) & $\beta$-coefficient ( $p$ value) \\
\hline \multicolumn{3}{|c|}{ For $\Delta$ Systolic blood pressure } \\
\hline Age & $0.183(0.011 *)$ & $0.003(0.968)$ \\
\hline Gender, male & $0.029(0.683)$ & $0.060(0.421)$ \\
\hline$\Delta$ Body mass index & $0.179(0.027 *)$ & $0.069(0.378)$ \\
\hline$\Delta$ Glucose & $-0.032(0.664)$ & $0.001(0.997)$ \\
\hline$\Delta \mathrm{AST}^{\dagger}$ & $0.078(0.328)$ & $-0.037(0.699)$ \\
\hline$\Delta \mathrm{ALT}^{\dagger}$ & $0.049(0.552)$ & $0.159(0.099)$ \\
\hline$\Delta \mathrm{GGT}^{\dagger}$ & $0.165(0.045 *)$ & $0.166(0.040 *)$ \\
\hline \multicolumn{3}{|c|}{ For $\Delta$ Diastolic blood pressure } \\
\hline Age & $0.139(0.061)$ & $-0.022(0.773)$ \\
\hline Gender, male & $0.088(0.238)$ & $-0.038(0.616)$ \\
\hline$\Delta$ Body mass index & $0.026(0.755)$ & $0.087(0.276)$ \\
\hline$\Delta$ Glucose & $-0.076(0.321)$ & $-0.012(0.879)$ \\
\hline$\Delta \mathrm{AST}^{\dagger}$ & $-0.093(0.263)$ & $-0.009(0.925)$ \\
\hline$\Delta \mathrm{ALT}^{\dagger}$ & $0.144(0.096)$ & $0.105(0.283)$ \\
\hline$\Delta \mathrm{GGT}^{\dagger}$ & $0.170(0.047 *)$ & $0.147(0.071)$ \\
\hline
\end{tabular}

DM, diabetes mellitus; AST, aspirate aminotransferase; ALT, alanine aminotransferase; GGT, gamma-glutamyl transferase. $\Delta$ (difference levels) means the values by subtracting the pre-study values from the post-study values.

AST, ALT and GGT were analyzed after log-transformation because of their skewed distributions.

Significance level: $* p<0.05$.

\section{Discussion}

Our study during a 1-year period found a significant and positive association between GGT and SBP level differences, but DBP, in a population of type $2 \mathrm{DM}$, independent of age, gender, BMI and other hepatic enzymes. This finding extends to type $2 \mathrm{DM}$ in that GGT may be a predictive biochemical marker at least for SBP changes. Notably, the impact of measured variables on SBP/DBP might be different between type $2 \mathrm{DM}$ and non-DM: while in non-DM, the effects of age and BMI on SBP and the associations of GGT with both SBP and DBP are in lines with prior reports (Nilssen et al. 1990; Ikai et al. 1994; Lee et al. 2002, 2003; Whelton et al. 2002; Stranges et al. 2005; Shankar and Li 2007), lack of age- or BMI-related effects and attenuation on the association of GGT with DBP, observed in type $2 \mathrm{DM}$, may be reflective of some specific pathophysiology of type $2 \mathrm{DM}$. Because DM is usually found together with OS (Ceriello 2006), the presence of OS may modify GGT functions unlike those in non-DM subjects. Furthermore, for example, premature aging or weight reduction, which is linked with OS, is known during the progression of DM (Preuss 1997; Wakabayashi and Masuda 2004), and this may partly explain our results on type $2 \mathrm{DM}$.

In summary, our study showed a positive association between GGT and SBP level differences in type $2 \mathrm{DM}$, similar to non-DM. However, the impact of GGT on measured variables including DBP among type 2 DM subjects can be different from that of non-DM subjects, suggesting that the presence of DM may attenuate the effects of GGT on increases in DBP. These results call for further study. 


\section{Acknowledgments}

This study was supported in part by a grant-inaid from the Foundation for the Development of the Community, Japan.

\section{References}

Ceriello, A. (2006) Oxidative stress and diabetes-associated complications. Endocr. Pract., 12, Suppl. 1, 60-62.

Ikai, E., Honda, R. \& Yamada, Y. (1994) Serum gamma-glutamyl transpeptidase level and blood pressure in nondrinkers: A possible pathogenetic role of fatty liver in obesity-related hypertension. J. Hum. Hypertens., 8, 95-100.

Lee, D.H., Ha, M.H., Kim, J.R., Gross, M. \& Jacobs, D.R. (2002) Gamma-glutamyltransferase, alcohol, and blood pressure: A four year follow-up study. Ann. Epidemiol., 12, 90-96.

Lee, D.H., Jacobs, D.R., Jr., Gross, M., Kiefe, C.I., Roseman, J., Lewis, C.E. \& Steffes, M. (2003) Gamma-glutamyltransferase is a predictor of incident diabetes and hypertension: The Coronary Artery Risk Development in Young Adults (CARDIA) Study. Clin. Chem., 49, 1358-1366.

Lee, D.H., Blomhoff, R. \& Jacobs, D.R., Jr. (2004) Is serum gamma glutamyltransferase a marker of oxidative stress? Free Radic. Res., 38, 535-539.
Nilssen, O., Forde, O.H. \& Brenn, T. (1990) The Tromso Study: Distribution and population determinants of gammaglutamyltransferase. Am. J. Epidemiol., 132, 318-326.

Preuss, H.G. (1997) Effects of glucose/insulin perturbations on aging and chronic disorders of aging: the evidence. J. Am. Coll. Nutr., 16, 397-403.

Shankar, A. \& Li, J. (2007) Association between serum gammaglutamyltransferase level and prehypertension among US adults. Circ. J., 71, 1567-1572.

Stranges, S., Trevisan, M., Dorn, J.M., Dmochowski, J. \& Donahue, R.P. (2005) Body fat distribution, liver enzymes, and risk of hypertension: Evidence from the Western New York Study. Hypertension, 46, 1186-1193.

Wakabayashi, I. \& Masuda, H. (2004) Relationship between obesity and atherosclerotic risk in elderly type 2 diabetic patients. Nippon Ronen Igakkai Zasshi, 41, 223-227 (in Japanese with English abstract).

Whelton, P.K., He, J., Appel, L.J., Cutler, J.A., Havas, S., Kotchen, T.A., Roccella, E.J., Stout, R., Vallbona, C., Winston, M.C. \& Karimbakas, J.; National High Blood Pressure Education Program Coordinating Committee. (2002) Primary prevention of hypertension: Clinical and public health advisory from The National High Blood Pressure Education Program. JAMA, 288, 1882-1888. 